Please quote as: Mauro, C.; Happle, T.; Sunyaev, A.; Leimeister, J.M.; Krcmar, H. (2010): From Medical Processes to Workflows: Modeling of Clinical Pathways with the Unified Modeling Language. Poster Presentation at the Third International Conference on Health Informatics (HealthInf 2010), January 20-23, 2010, Valencia, Spain. 


\title{
FROM MEDICAL PROCESSES TO WORKFLOWS Modeling of Clinical Pathways with the Unified Modeling Language
}

\author{
Christian Mauro, Tobias Happle, Ali Sunyaev, Helmut Krcmar \\ Information Systems, Technische Universitaet Muenchen, Boltzmannstr. 3, 85748 Garching, Germany \\ mauro@in.tum.de,tobias.happle@gmx.de,sunyaev@in.tum.de,krcmar@in.tum.de \\ Jan Marco Leimeister \\ Information Systems, Universitaet Kassel, Nora-Platiel-Strasse 4, 34127 Kassel, Germany \\ leimeister@uni-kassel.de
}

Keywords: Clinical Pathways; Workflows; UML; Workflow Management Systems; Process Modeling.

\begin{abstract}
Clinical pathways describe treatment processes within a hospital. They can be used as process models, which can be controlled by implemented workflow models in information systems. This enables (semi-) automated processes, and they are therefore high potential for an improved quality management and seamless IT support. Surprisingly, there are no published process models that describe the implementation of clinical pathways in an information system while taking into account the characteristics of health care specifics. We bridge this gap by proposing a process model using UML as modeling language.
\end{abstract}

\section{INTRODUCTION}

Clinical pathways specify concrete treatment activities for patients with identical diagnoses or for patients diagnosed differently but treated by employing the same therapy (Engemann and Strobel, 2005). This standardization of the activities serves as a cost saving factor because of its short delay time as well as its quality assurance. Process descriptions can be populated in hospital information systems or in autonomous workflow management systems (WfMS) (Allen and zur Mühlen, 2000) through editors for effective information technology (IT) support of the pathways. Hereby, essential parts of the necessary communication and coordination between the actors can be automated and the effectiveness, as well as the efficiency of the processes, can be improved.

Despite the advantages of this process control, there is no process model published that describes the implementation of clinical pathways in information systems, considering the characteristics of the clinical environment, such as the robust clinical pathway structure in treatment phases. This paper bridges this gap by introducing a process model using the Unified Modeling Language (UML) 2.0, which is suitable for the implementation of clinical processes (Becker, 2006), (Lang et al., 2006) and is a widespread official standard of the Object Management Group.

\section{PROCESS MODEL}

Models serve as a simplified description of reality. In order to reduce complexity or to increase the comprehensibility of the figures, one should employ different views and modeling layers in the representation of these systems (Gadatsch, 2005). One is able to distinguish three modeling layers: business process, functional workflow and technical workflow, which are differentiated by their proximity to the IT (Wittges, 2005). In contrast to the business process which describes the activities to be executed in a pure functional manner, the functional workflow layer concentrates on the description of work processes with regard to the requirements that result from the technical support of the execution of workflows by an information system (Gadatsch, 2005), (Jablonski et al., 1997). Due to the different focus of both modeling layers (functional process vs. implementation supported by IT), the use of successive modeling of a real process is recommendable: first within the business process layer and then in the workflow layer. In the end, the functional and producer-independent workflow- 
model is transformed by a workflow-editor into a producer-specific model which can be automatically executed (technical workflow layer). For the sake of clarity, the process model for transformation of clinical pathways will be divided hereafter into modeling layers.

\subsection{Modeling of Clinical Pathways in the Business Process Layer}

The modeling of clinical pathways in the business process layer is organized in phases which will be explained in the next sections.

\subsubsection{Pathway Selection and Process Analysis}

The IT implementation of clinical pathways is, in contrast to payment in kind processes, not always accomplishable because of the high variation in the process input factors (Gadatsch, 2005), (Schneeweiß, 2002). The high variation of process relevant properties, such as age, sex, or diverse previous diseases, hinders the prediction and the adherence of particular treatment processes and treatment outcomes. In order to implement clinical pathways in information systems, taking into consideration the costs resulting from it, one can employ only pathways with patients which promise cost saving potentials because of their frequent appearance and/or the corresponding treatment costs or because of adequate homogenous patient groups, whose processes differ insignificantly (Fischbach and Engemann, 2006), (Thun, 2006).

One-person interviews with selected professionals involved in the process (from nursing, medical or administrative departments) are documented in order to collect information about the current treatment processes. Organizational delays often cause at least a two-day duration of the interviews. Both rounds of talks should be at least three working days away from each other since during this time period the start of the modeling should be planned. Thus, knowledge gaps in the process execution can be identified and prompted in the following interviews. The interviews must be recorded on audio tapes because the complexity of the processes makes written documentation difficult during long talks. Documents relevant for the process execution should also be provided to be analyzed.

\subsubsection{Cases - Preliminary Design}

Since with a single clinical pathway different disease patterns can possibly be treated and these variations can be demanded during the process execution, different alternatives of the pathway must be distinguished and modeled separately. Therefore, one can discern cases which summarize patient groups of one pathway, for whom an identical treatment process is obligatory. Business partners (for instance, general practitioners or medical specialists) initiate the cases which, in order, determine to a greater extent, the starting point of the model. Activity diagrams and standard elements in UML 2.0 are used for modeling of the various cases.

Treatment processes in the clinical field exhibit robust structure of the activities to be executed into treatment phases; especially in post-operative treatment processes, the activities are also structured into treatment days. The treatment phase in which a process is being executed has an impact on the concrete execution of some diagnostic processes too. Therefore, the activity diagrams necessary for the modeling are, at first, divided into treatment days and phases in order to ease the further matching. Since UML 2.0 provides no suitable elements for visualization of time spans within an activity diagram, and isolated modeling of the days and phases (for example in separate activity diagrams) is usually not possible because of the large number of interdependencies, day and phase changes are presented as a Fork/Join element. The naming of the activities and the actions are expressed from a clinical institution's point of view (Oestereich et al., 2003). For instance, "dispense medicaments" would be used instead of "receive medicaments."

In the context of examination and approval processes, information flows are presented as Send/Receive UML objects. When using Send/Receive objects, one must note from which organizational unit the signal originates and for which one it is intended. Both objects are connected through an information flow. Because of the acute cases of emergency and the chronic overload of the clinical personnel, an important condition for the composition of clinical treatment processes is their flexible and appropriate adaptation. Thus, the workload of the necessary resources determines, to a greater extent, the time for the execution of activities that are not critical (especially in post-operative phases). In order to achieve the necessary flexibility in the form of a modeling paradigm, one would better use parallelization of actions and activities instead of sequential arrangement if the latter is not compulsory because of the corresponding interdependencies.

Knowledge gaps in the process execution are noted during the modeling as notices in the activity diagram and in a notice list. These gaps are handled as checklists during the talks that follow. 


\subsubsection{Final Case Design and the Role Model}

During the modeling of the case preliminary design, organizational and role models are produced simultaneously, for which the relevant organizational units within a class diagram are modeled by using an organigram. After all interviews are completed, an actor model is developed within a use case diagram. The model contains all identified roles and additional features for which an assignment from activities to people is required. The modeled organizational units are detailed by the identified actors.

Subsequently, the pathway on the business process level is completed after the modeling of the case final design. For that purpose, activities are consolidated, the process logic is specified, and the roles and functions contained in the process are displayed by Swimlanes, which represent the schedule of responsibilities. In case different actors can process activities or decisions about the process sequence, they are placed on the strip line of the Swimlanes, or if there are more than two different actors, tags are intended to represent them. Tags can also serve, for instance, as containers for additional information describing the content of the activities. In addition, the creation of specific stereotypes, which change the visualization of the activities, depending on the tags, might be reasonable. Finally, a glossary of the used technical terms is created.

\subsection{Modeling of Clinical Pathways on Workflow Level}

After the pathway has been modeled on the business process level, its modeling on technical workflow layer follows. The modeling of single cases is implemented in separate activity diagrams, whereas the modeling is focused on the organizational, operative, and data-oriented content (Lang et al., 2006). Organizational aspects are very significant because of the highly specialized job descriptions in health care (Ziegenbein, 2001). The important meaning of the data-oriented aspects results mainly from extensive documentation requirements and the generally high information requirements of patients' treatment processes.

\subsubsection{Representation Elements}

A central element of the representation within the technical workflow layer is the work item - a stereotype of the UML class Action that encapsulates the interaction of a system with human actors in a black box. The element work item can be interpreted as an IT representative of an activity to be processed in a work list handler, and it enables the interaction between a user and the information system. The work item conceals the concrete technical implementation of the communication, but despite that, allows a simple representation of interactions which control the execution of the pathway. Generally, three basic use cases of an interaction are possible: a notification about the present tasks without additional presentation and/or documentation of data, the optional, and the required presentation and/or documentation of information. The actors, who process the work item, are modeled explicitly and attached to it. Moreover, for each of them the corresponding organizational unit is indicated.

\subsubsection{Modeling in the Technical Workflow Layer}

The modeling in the technical workflow layer is basically divided into three phases. In the first one, the sub-processes which are to be implemented on the system are selected and holistically modeled. Very suitable for implementation on this layer are diagnostic methods, periodic or recurrent processes (such as measurement and documentation of vital parameters) and common administrative processes, in whose execution a multitude of actors participates and which possesses a sufficiently high grade of structuring of the work processes.

During the implementation of multiple pathways, these sub-processes are separated and categorized into delimitable use cases and specific variants in order to develop standardized processes that can be reused in a variety of pathways. However, these process libraries that originate from them are not the subject of this brief paper. If, however, only one pathway is transferred into an information system, then the development of standards and variants is not urgently required but still reasonable because such complex pathways can be structured systematically.

After the creation of a domain model or a state model, the complete pathway including the necessary process logic is modeled into an activity diagram. Thereby, the subdivision into phases should be kept because this structure is used, for example, for the assignment of success factors, and the following treatment steps are activated partly on presentation of particular success factors, whereby this structure is exceptionally suitable for control of the treatment progress or for regulation and enabling the following treatment phases. 


\section{SUMMARY AND OUTLOOK}

A process model was presented which describes the implementation of developed (paper-based) pathways in an information system. Unified Modeling Language 2.0 was used as a modeling language. Initially, clinical pathways were modeled in their functional sequence (business process layer), afterwards selected subsequences were implemented in the second modeling layer in regard to IT requirements (functional workflow layer).

The effort during the implementation of numerous pathways in an information system can be considerably reduced by the employment of patterns for subsequences and for the sequential structure of the whole pathway. Due to space restrictions, the approach for the identification and systematization of clinical processes in a process library is not part of this paper. The efforts implied by the implementation of clinical pathways can be considerably reduced by the procedure model and the approach for development of a process library.

In the present research paper, problems with respect to the implementation of clinical pathways in an information system have been examined but not the technical capabilities of such implementation. Therefore, further research must clarify which requirements need to be met by such an information system and especially by a workflow editor within the information system, i.e., which technology solutions are suitable for the implementation of process control in the clinical field. This research paper has shed light on the significance of comprehensive pathway templates; however, it must be clarified in further research how such pathway templates can be identified and delimited. The verification of the approach methodology described here on other clinical pathways is also a goal of further research.

\section{REFERENCES}

Allen, R. \& zur Mühlen, M. (2000) Embedded vs. Autonomous Workflow - Putting Paradigms into Perspective. IN Fischer, L. (Ed.) Excellence in Practice IV - Innovation and Excellence in Workflow and Knowledge Management. Lighthouse Point.

Becker, K. (2006) Prozessanalyse zur Entwicklung integrierter Behandlungspfade. IN Eckardt, J. \& Sens, B. (Eds.) Praxishandbuch integrierte Behandlungspfade - Intersektorale und sektorale Prozesse professionell gestalten. Heidelberg, Economica Verlag.
Eckardt, J. (2006) Was sind integrierte Behandlungspfade. IN Eckardt, J. \& Sens, B. (Eds.) Praxishandbuch integrierte Behandlungspfade - Intersektorale und sektorale Prozesse professionell gestalten. Heidelberg, Economica Verlag.

Engemann, R. \& Strobel, U. (2005) Behandlungspfade zur Unterstützung der ambulanten und kurzstationären sowie der fast-track-Chirugie. Viszeralchirugie, 40, 95-103.

Fischbach, W. \& Engemann, R. (2006) Interdisziplinärer Behandlungspfad bei kolorektalem Karzinom. Der Internist, 47, 720-728.

Gadatsch, A. (2005) Grundkurs GeschäftsprozessManagement, Wiesbaden, Vieweg Verlag.

Greiffenberg, S. (2004) Methodenentwicklung in Wirtschaft und Verwaltung, Hamburg Verlag Dr. Kovač.

Jablonski, S., Böhm, M. \& Schulze, W. (1997) Workflow Management - Entwicklung von Anwendungen und Systemen, Heidelberg, dpunkt.verlag.

Kazmeier, J. (1998) Modellierung soziotechnischer Systeme im Requirements Engineering bei betrieblicher Software. Institut für Informatik. München, Technische Universität München.

Lang, M., Bürkle, T., Laumann, S., Bauer, J. \& Prokosch, H.-U. (2006) Modeling the Radiology Workflow: A hands-on Comparison on established Process Modeling Languages. 51. Jahrestagung der GMDS Leipzig. German Medical Science.

Oestereich, B., Weiss, C., Schröder, C., Weilkiens, T. \& Lenhard, A. (2003) Objektorientierte Geschäftsprozessmodellierung mit der UML, Heidelberg, dpunkt.verlag.

Schneeweiß, C. (2002) Einführung in die Produktionswirtschaft, Berlin, Springer Verlag.

Thun, S. (2006) Projektmanagement zur praktischen Umsetzung von integrierten Behandlungspfaden. IN Eckardt, J. \& Sens, B. (Eds.) Praxishandbuch integrierte Behandlungspfade - Intersektorale und sektorale Prozesse professionell gestalten. Heidelberg, Economica Verlag.

Wittges, H. (2005) Verbindung von Geschäftsprozessmodellierung und WorkflowImplementierung, Universität Hohenheim.

Ziegenbein, R. (2001) Klinisches Prozessmanagement Implikationen, Konzepte und Instrumente einer ablauforientierten Krankenhausführung, Münster. 